\title{
KEYNES ON PROBABILITY
}

A Treatise on Probability. By J. M. Keynes. London, Macmillan and Co., 1921. xi +466 pp.

Starting as a Fellowship Dissertation, interrupted by the war, preceded by economic publications widely circulated, and now published, apparently without all the finishing touches the author had liked to bestow, Keynes's Treatise on Probability is (see p. 433) the first systematic work in the English language on the logical foundations of probability since Venn's Logic of Chance (1866). Carefully documented throughout, the work closes with a 25 page bibliography which, though not pretending to completeness, is a much longer list of what has been written about probability than can be found elsewhere (p. 431). As the author has made these statements himself, the reviewer has but to quote. Two other quotations may be of interest: (1) "The theory of 'Testimony,'-of the combination of the testimony of witnesses,- - has occupied so considerable a space in the traditional treatment of Probability that it will be worth while to examine it briefly. It may. however, be safely said that the principal conclusions on the subject set out by Condorcet, Laplace, Poisson, Cournot and Boole are demonstrably false. The interest of the discussion is chiefly due to the memory of these distinguished failures" (p. 180). Never perhaps since ancient biblical times has such a redoubtable army of philistines been so deftly slain (Judges, XV, 15). And (2) in speaking of Poincaré's opinions on probability in his Calcul des Probabilités and Science and Hypothesis, "neither of which appears to be in all respects a considered work," * we find (p. 84): "He seems to endeavor to save his reputation as a philosopher by the surrender of probability as a valid conception, without at the same time forfeiting his claim as a mathematician to work out probable formulæ of practical importance." Apparently our author little realizes that, stumbling in the dark, he has hit upon a very clever characterization of Poincarés real philosophic system-pragmatism. The Fellowship Dissertation stage still lingers in spots.

To understand Keynes one has constantly to bear in mind that he is of the philosophic not of the mathematical school, that he derives from Leibniz, Hume and Venn rather than from Bernoulli, Laplace, and Charlier. He is seeking to lay a logical foundation for probability and to examine that foundation in the light of a wide reading of philosophic, mathematical, and statistical works on probability. $\mathrm{He}$ is not uninfluenced by the

* Keynes's request (p. 427) for generosity on the part of his readers is not so likely to be granted as if his own manners conformed to that spirit; besides, when writing a really critical treatise an author defeats his own ends unless he so writes that readers need not have to discount either his scientific exposition or his professional manner. If taken literally, Keynes's request must undermine our confidence in his own belief that he has accomplished the very thing that he set out to do! 
Russell-Whitehead school of rigorous mathematics. Indeed, Part II, Fundamental Theorems, pp. 115-214, is much cast in their style. Much of this part is hard reading because so compact, but he would be rash indeed who would compare its difficulty with the Principia Mathematica; the resemblance is, fortunately for most of us, rather to the earlier Principles of Mathematics. Other parts are hard reading to one not used to philosophic discourse. For example (p. 36) the author is trying to be very explicit and very clear on a very important point: "A book bound in blue morocco is more like a book bound in red morocco than if it were bound in blue calf; and a book bound in red calf is more like the book in red morocco than if it were blue calf." Whether it is a deficiency in our visual or in our tactile sense or, even worse, in our ratiocinative powers which makes this statement, whether in or out of its context, unintelligible has been a distressing trilemma ever since we read it. Or is it the War or the Peace or only the Fellowship Dissertation again?

By this time not only the author but our readers will have perceived that we are not fit to review this book. There are others who appear to share our predicament. The keen mind of one of our ablest statisticians, Arne Fisher, rebels at Keynes's criticisms and shows its fire in the last section (pp. 277-279) of his Mathematical Theory of Probabilities, 2d edition, Macmillan, 1922. It would be interesting to quote Fisher at some length, for what an author will incorporate in a text often carries more weight than what a reviewer may write, but let the readers of the BuLleTiN look up the reference and read the whole. Also let them not take too seriously what Mr. Fisher or I may say. Neither of us is primarily a philosopher, economist or logician; we have both been under the necessity, an enjoyable necessity, of using probability in a wide range of problems. The attitude toward a subject of those who use it is different from that of those who think on it. This phenomenon is well known in mathematics. The progress towards the greater use of a subject is made by those who use it, the progress towards its greater digestion and codification is made by those who think on it. Although the attitude and the method of work of these two camps are different, often so different as to be mutually incomprehensible, it is not necessary that they be mutually destructive.

Some of Keynes's comments on illustrious investigations and originators in probability might have been cast in far different language had he realized the essentially pragmatic, the unconsciously pragmatic, point of view of the scientific as contrasted with the philosophic investigator. I have recently carefully reread Laplace's Essai philosophique sur les Probabilités, and I cannot refrain from noting what appears to me a patient, critical, pragmatic, and tentative attitude on the part of Laplace. His treatment whether of the Law of Non-sufficient Reason, of the Law of Succession, or even of the previously mentioned "Testimony" seems open-minded and fair. But I can understand how it may seem very different to Keynes. A scientist writes a direct, clear style with definite statements; he does not qualify everything indefinitely even when he realizes that qualification would be necessary for generalization beyond the case in hand. He writes for his confrères, who understand his style. Take the case of many a 
physicist who has written on that particular statistical theorem known as the Law of the Equipartition of Energy, and who has not, because he has not thought it necessary, made the statement that the law cannot possibly be true * because of the values of the ratio of the specific heats. To the philosopher or economist who may rarely make a definite statement, and who from the nature of his work and his interests perhaps cannot, the definite style of the scientist appears dogmatic, rather than pragmatic, and altogether damnable-but it is written: Judge not, that ye be not judged.

I do not, however, wish to give the impression that Keynes's book is not worth reading and study, that it was not worth doing and on the whole well done. The reason that $I$ have dealt at such length with certain characteristics which mar the work is because, writing for those who may easily be irritated by these blemishes, I wish to explain them in the hope of reducing the irritation to such a point that the readers of this review will persevere through them to the real enjoyment and instruction that I have found in many parts of the work. The analysis of the fundamental concepts connected with the category of probability (Part I) is in many respects illuminating. $\dagger$ The logical treatment, in the style of Russell, of the fundamental theorems is also appealing (Part II). The general advice to "watch your step" is perhaps much less necessary to the scientist than to the philosopher because the former is dealing, as Poincare frankly says in language only partly understood by the author, with specific cases, and perhaps only tentatively, where external indicia of impending danger or safety are not lacking, whereas the latter is developing generalities that may all too readily entice him without warning into real trouble.

There is much to interest the statistician in the discussion of the different frequency distributions resulting therefrom (pp. 194-214). Highly valuable, too, is the discussion, so far as it goes, of the normal or Gaussian law and of the Tchebycheff criterion which is so much safer than the probable error in all cases where the observations are few or are not distributed according to the normal law (pp. 351-359). The analysis of the ideas of Lexis is good but could have been carried further to include Charlier and the whole Scandinavian school who have been very active in the last forty years and who seem to be neglected by Keynes, and not by him alone. To the long bibliography one might add the essay of Royce on The mechanical, the historical and the statistical, ScIEnce, April 17, 1914, pp. 551-566. There are points here of philosophic import that seem not to have been covered by Keynes and might be worked into his system. Moreover some might feel that the Statistical Mechanics of Gibbs (1901), when viewed philosophically, particularly with respect to the meaning of equi-

* See the comment of Gibbs in the preface to his Statistical Mechanics, especially $\mathrm{p} . \mathrm{x}$.

$\dagger$ Keynes seems to belong rather to the a priori than to the a posteriori school of thought. This is natural from his philosophical, logical, analytical viewpoint. To adopt the a posteriori attitude consistently in a didactic treatise is difficult and rare; Thiele tried it relentlessly and I think that not many read his work, that fewer find it easy to read. 
librium and of natural systems (whether physical or economic) and collated with the very general viewpoint of Royce and of C. S. Peirce (whose maturer work Keynes does not cite), might be worthy of at least a bibliographic reference by an author who is setting up a category of probability. However, it would be unreasonable to expect any discussion of categories to reach nearer the date of issue than about 50 years, just as one can hardly expect the full treatment of the necessary and sufficient conditions justifying a new analytical method to follow right on the heels of the introduction of such a method by the physicist (Fourier, Heaviside).

E. B. WiLSON

\section{BLASCHKE ON DIFFERENTIAL GEOMETRY}

Vorlesungen über Differentialgeometrie und geometrische Grundlagen von Einstein's Relativitätstheorie. Volume 1, Elementare Differentialgeometrie. By W. Blaschke. Berlin, Julius Springer, 1921. $\mathrm{x}+230 \mathrm{pp}$.

This volume is the first of a series of three which the author plans to publish under the first part of the title given above. It is devoted in part to the classical theories of the differential geometry of curves and surfaces, and in part to some very interesting special chapters of these theories with which the author himself has been especially occupied. In his preface Professor Blaschke says that this first volume contains a presentation of the properties of curves and surfaces which are invariant under the group of motions, that the second will be devoted to affine differential geometry, and that a third will present the geometrical theories of Riemann and Weyl, which are so closely related to the Einstein theory of gravitation.

There are two interesting features of the book that attract one's attention at the very start. The first is the consistent use of vector notations. All of us who have lectured on differential geometry have doubtless been impressed with the great economies in presentation which these notations would afford. I have myself hesitated to use them in lecture courses because of the loss of time necessitated at the beginning of a course by explanations to hearers who have had no experience with vector notations, and because of the slight element of awe and mystification which these notations seem to arouse in the minds of those who have had only a limited acquaintance with them. After reading Professor Blaschke's book, I have grave doubts of the correctness of my attitude. The properties of vectors which one needs in differential geometry are few and simple, and he has demonstrated that they may be clearly and concisely explained as the occasions for their use arise. When one considers the many applications of vector analysis in other domains as well as in geometry, it seems clear that we should acquaint our students with the elements of the subject at the earliest possible moment. Mathematical physicists usually shy away from abstract mathematical notations, as they did from the noneuclidean theories of space before the recent revolution. Is it not curious that they should be the leading advocates of the vector analysis notations 